\title{
Changing epidemiology of hepatitis A virus in Indian children
}

This article was published in the following Dove Press journal:

Vaccine: Development and Therapy

18 January 2014

Number of times this article has been viewed

\author{
Vidya Arankalle' \\ Monjori Mitra ${ }^{2}$ \\ Sheila Bhave ${ }^{3}$ \\ Apurba Ghosh ${ }^{2}$ \\ Sundaram Balasubramanian ${ }^{4}$ \\ Suparna Chatterjee ${ }^{5}$ \\ Jaydeep Choudhury ${ }^{6}$ \\ Amarjeet Chitkara ${ }^{7}$ \\ Ganesh Kadhe ${ }^{8}$ \\ Amey Mane ${ }^{8}$ \\ Sucheta Roy ${ }^{8}$ \\ 'Department of Virology, National \\ Institute of Virology, Pashan, Pune, \\ Maharashtra, India; ${ }^{2}$ Department \\ of Pediatrics, Institute of Child \\ Health, Kolkata, West Bengal, India; \\ ${ }^{3}$ Department of Pediatrics, KEM \\ Hospital and Research Center, Pune, \\ Maharashtra, India; ${ }^{4}$ Department \\ of Pediatrics, Kanchi Kamkodi \\ Child Trust Hospital (KKCTH), \\ Nungambakkam, Chennai, Tamil Nadu, \\ India; ${ }^{5}$ Department of Pharmacology, \\ Institute of Post Graduate Medical \\ Education and Research (IPGMER) \\ and Seth Sukhlal Karnani Memorial \\ (SSKM) Hospital, Kolkata, West \\ Bengal, India; ${ }^{6}$ Department of \\ Pediatrics, Sri Aurobindo Seva Kendra \\ (EEDF Hospital), Kolkata, West Bengal, \\ India; ${ }^{7}$ Department of Pediatrics, \\ Sarvodaya Childcare, Pitampura, Delhi, \\ India; ${ }^{8}$ Medical Affairs Department, \\ Wockhardt Ltd, Mumbai, Maharashtra, \\ India
}

Correspondence: Monjori Mitra Department of Pediatrics, Institute of Child Health, II, Dr Biresh Guha Street, Kolkata, West Bengal, India Email monjorim@medclinsearch.com
Abstract: Previous studies from India have observed an increased incidence of hepatitis A virus (HAV) infection in the adult and adolescent population compared with children, indicating a shift in epidemiology of HAV. However, no HAV seroprevalence study has been conducted in India over the past decade. This prospective, multicenter, cross-sectional study was conducted in 928 children (aged 18 months to 10 years), to estimate the age-related seroprevalence of HAV across different regions of India. The present study also evaluated the impact of various factors such as age, socioeconomic class (SEC), education, source of drinking water, and excreta disposal on HAV seroprevalence. Overall, 348 (37.5\%) children were seropositive for anti-HAV antibodies. Seroprevalence of HAV in the 6- to 10-year age group (50.3\%) was higher $(P=0.000)$ than in the 18-month to 6-year age group (30.3\%). SEC and educational status of the parents were significantly associated with HAV seropositivity ( $P=0.000$ for both). An increase in seroprevalence was observed with an increase in age in all SECs $(P<0.000-0.001$ for all $)$ except upper SEC $(P=0.124)$. Fewer subjects using a private toilet within the house $(33.1 \%)$ were seropositive than subjects using an open field (75\%) for excreta disposal. In conclusion, the present study observed a transition in the seroprevalence of HAV, with a higher seropositivity in older children. Age, SEC, source of drinking water, and education status of parents were significantly associated with HAV seroprevalence.

Keywords: children, hepatitis A, infectious disease, seroprevalence

\section{Introduction}

Hepatitis A is an acute, self-limiting disease of the liver caused by the hepatitis A virus (HAV), and there are $>1.5$ million cases worldwide annually. ${ }^{1}$ The World Health Organization (WHO) estimates that the global burden of viral hepatitis A increased from 177 million in 1990 to 212 million in $2005 .{ }^{2}$ Overall, 35,245 HAV-related deaths were estimated in $2005 .^{2}$

India is hyper-endemic for HAV infection. Studies conducted in the 2000 s observed that nearly $90 \%$ of adolescents, adults, and most children acquired immunity to HAV infection in their preschool years. ${ }^{3}$ However, recent studies have indicated a shift in epidemiology of HAV infection over the past decade. ${ }^{4,5}$ Chitambar et $\mathrm{al}^{6}$ demonstrated a significant $(P<0.05)$ shift in epidemiology of HAV infection among children aged 5-10 years from $96.7 \%$ in 1983 to $85.1 \%$ in 1995 . Murhekar et al ${ }^{7}$ showed a decrease in anti-HAV seropositivity among children aged $<10$ years between 1989 and 1999 (decrease in seropositivity: $80 \%$ in 1989 to $60 \%$ in $1999 ; P=0.019$ ). Anti-HAV antibodies were detected in $100 \%$ of newborns 15 years ago as a result of a rise in maternal exposure to HAV. Recent studies have shown a fall in the number of cases 
to $50 \%-60 \% .{ }^{8}$ Acharya et $\mathrm{al}^{9}$ opined that improved hygienic and socioeconomic conditions led to a shift in epidemiology of HAV infection.

Incidence of HAV is closely related to socioeconomic development, with prevalence of anti-HAV varying from $<50 \%$ in high-income regions (Western Europe, Australia, New Zealand, Canada, the USA, Japan, Republic of Korea, Singapore) to as high as $>90 \%$ in low-income regions (sub-Saharan Africa, parts of South Asia). Most middle-income regions in Asia, Latin America, Eastern Europe, and the Middle East have a mix of intermediate ( $>50 \%$ immunity by 15 years) and low ( $<50 \%$ immunity by 30 years) prevalence of anti-HAV antibodies. ${ }^{10}$ Syed et $\mathrm{al}^{11}$ suggested a shift in HAV infection epidemiology in India, like other countries in southeast Asia and People's Republic of China, over the past 20 years from high to moderate endemicity and from moderate to low endemicity due to community living conditions and occupation. In India, there is a growing body of evidence that children from low socioeconomic classes (SECs) continue to have a high prevalence of anti-HAV antibodies. ${ }^{12-15}$ Dutta et al ${ }^{16}$ reported considerably lower HAV seroprevalence among children (0-12 years) whose parents were educated and in children with improved sanitary conditions. Arankalle et $\mathrm{al}^{13}$ reported that, over a 16-year observation period, lower SEC was associated with a 23-fold higher risk of HAV infection. HAV seropositivity was $64.5 \%$ in a population from a higher SEC compared with $85.4 \%$ from a lower SEC. ${ }^{14}$

Hepatitis A is a vaccine-preventable disease. Although studies conducted in the past have provided adequate evidence of changing HAV epidemiology, ${ }^{13,17}$ recent data are required for national vaccine strategy policy making. The present multicenter study evaluated seroprevalence of HAV among children across different geographical locations of India. The impact of various factors, such as age, SEC, source of drinking water, and education status of parents, on HAV seroprevalence was investigated in Indian children between 18 months and 10 years of age.

\section{Materials and methods \\ Ethics statement}

The study protocol was reviewed and approved by the individual Independent Ethics Committees/Institutional Review Boards (IECs/IRBs) (Ethics Committee of Childs Trust Medical Research Foundation, Chennai; Ethics Committee King Edward Memorial [KEM] Hospital and Research Center, Pune; and Ethics Committee of Institute of Child Health [ICH], Kolkata). The study was conducted in accordance with the guidelines of the International Conference on Harmonisation of Technical Requirements for Registration of Pharmaceuticals for Human Use/Good Clinical Practice (GCP), and Indian Council of Medical Research (ICMR), and the Declaration of Helsinki. ${ }^{18}$

\section{Study characteristics}

This was a prospective, cross-sectional, multicenter study conducted in five different centers (ICH, Kolkata; Sree Aurobindo Seva Kendra-Economic Entrepreneurship Development Foundation [EEDF], Kolkata; KEM Hospital, Pune; Kanchi Kamakoti Childs Trust Hospital [KKCTH] Chennai; and Sarvodaya Child Care [SCC], New Delhi) across four cities (New Delhi, Kolkata, Pune, and Chennai) between September 2011 and July 2012.

\section{Inclusion and exclusion criteria}

Children (18 months to 10 years) seeking medical treatment for a health problem or minor non-infective illness or attending a follow-up visit or health examination and requiring blood draw for any indication were eligible for the study. All subjects and/or their parents gave written consent to participate in the study. Children with a history of hepatitis A vaccination or current symptoms of viral hepatitis/chronic hepatitis were excluded from the study.

\section{Data collection}

A thorough physical examination of the eligible children was performed. The following details were documented:

- medical history;

- area of residence (such as having a home/homeless, rural/ urban, if urban whether in an urban slum area/urban nonslum area [an urban non-slum area is defined as a statutory place with a municipality, corporation, cantonment board, or notified town area committee; an urban slum area is defined as a compact area with at least a population of 300/60-70 households of poorly built congested tenements, in an unhygienic environment, usually with inadequate infrastructure lacking proper sanitary and drinking water facilities]);

- home sanitary conditions, such as source of drinking water (tap water, river water, well water, or hand pump) and drinking water treatment (filtered water, boiled water, ultraviolet [UV]/reverse osmosis [RO]-based purified water, or untreated water);

- excreta disposal (private toilet within the house, private toilet outside house, public toilet, or open field); 
- education status (professional/honors, graduate/postgraduate, intermediate/post-high school diploma, high school certificate, middle school certificate, primary school certificate, or illiterate); and

- occupation of parents/guardians (professional, semiprofessional, clerical/shop owner/farmer, skilled worker, semi-skilled worker, unskilled worker, or unemployed).

Kuppuswamy's scale was used for evaluating the SEC by summing up the score for occupation of the parents/ guardians; education of parents/guardians; and family income. ${ }^{19}$

\section{Seroprevalence}

Blood samples of subjects were collected and the serum samples were screened for the presence and quantitation of total HAV antibodies using enzyme-linked immunosorbent assay (ELISA) AxSYM ${ }^{\circledR}$ HAVAB $^{\circledR}$-M 2.0 (Abbott Laboratories, Abbot Park, IL, USA). All the tests were conducted centrally in collaboration with the National Institute of Virology, Pune, India. Total anti-HAV levels $>0.80 \mathrm{mIU} \mathrm{mL}^{-1}$ were considered to be seropositive.

\section{Statistical analysis}

All demographic and socioeconomic parameters were summarized using descriptive statistics. Association between seroprevalence and various factors of sanitation and SEC (separate and combined) was analyzed using the $\chi^{2}$ test. Binary logistic regression using the likelihood model was performed for seroprevalence and various factors. A $P$-value of $<0.05$ was considered to be statistically significant. The overall effect of all parameters with HAV seroprevalence were evaluated with $2 \log$-likelihood, Cox and Snell $R^{2}$, and Nagelkerke $R^{2}$ tests. Statistical analysis was performed using SPSS 16 software (IBM Corporation, Armonk, NY, USA).

\section{Results}

The demographic details of subjects are presented in Table 1. A total of 928 children ( $N=272$ aged 18 months to 3 years; $\mathrm{N}=322$ aged $3-6$ years; $\mathrm{N}=334$ aged $6-10$ years) were enrolled. Based on the Kuppuswamy SEC scoring system, 69 belonged to a lower SEC, 209 to an upper lower SEC, 250 to a lower middle SEC, 269 to an upper middle SEC, and 131 to an upper SEC. Overall, seropositivity varied between different centers: New Delhi had the highest number of seropositive cases $(32 / 56 ; 57.1 \%)$, followed by Pune $(101 / 240$; $42.1 \%$ ). Heterogeneous pockets of susceptible individuals co-existed in different areas of Kolkata. The seropositivity
Table I Demographic profile of subjects

\begin{tabular}{lllll}
\hline $\begin{array}{l}\text { Study } \\
\text { center }(\mathbf{N})\end{array}$ & $\begin{array}{l}\text { Age } \\
(\text { year })\end{array}$ & $\begin{array}{l}\text { Female, } \\
\mathbf{n}(\%)\end{array}$ & $\begin{array}{l}\text { Height } \\
\mathbf{( c m})\end{array}$ & $\begin{array}{l}\text { Weight } \\
(\mathbf{k g})\end{array}$ \\
\hline EEDF $(72)$ & $5.4 \pm 2.6$ & $26(36.1)$ & $111.8 \pm 18$ & $19.0 \pm 7.5$ \\
ICH $(300)$ & $4.6 \pm 2.4$ & $109(36.3)$ & $104.5 \pm 21.8$ & $15.4 \pm 6.2$ \\
KKCTH (260) & $4.6 \pm 2.3$ & $92(35.4)$ & $104.3 \pm 22.1$ & $17.3 \pm 10.2$ \\
KEM (240) & $4.8 \pm 2.4$ & $108(45)$ & $102.7 \pm 21.6$ & $18.7 \pm 15.7$ \\
SCC (56) & $5.2 \pm 3$ & $19(33.9)$ & $107.4 \pm 27.5$ & $19.7 \pm 12.4$ \\
Total (928) & $4.7 \pm 2.4$ & $354(38.1)$ & $106.1 \pm 22.2$ & $17.3 \pm 11$ \\
\hline
\end{tabular}

Note: Data are presented as mean \pm SD unless otherwise indicated.

Abbreviations: EEDF, Economic Entrepreneurship Development Foundation (Sree Aurobindo Seva Kendra; Kolkata); ICH, Institute of Child Health (Kolkata); KEM, King Edward Memorial Hospital (Pune); KKCTH, Kanchi Kamakoti Childs Trust Hospital (Chennai); SCC, Sarvodaya Child Care (New Delhi); SD, standard deviation.

varied from $17 \%(12 / 72)$ to $48.3 \%(145 / 300)$ in the two centers of Kolkata. In Chennai, seropositivity was observed in $22.3 \%(58 / 260)$ of the subjects.

The number of seropositive cases increased with age across all study centers (Figure 1). The overall seroprevalence of HAV in the group aged 6-10 years $(50.3 \%)$ was significantly higher $(P=0.000)$ than in the group aged 18 months to 6 years $(30.3 \%)$. The seroprevalence of HAV in different age groups (18 months to 6 years and 6-10 years) and SECs showed a significant increase in all age groups across different SECs $(P<0.000-0.001$ for all $)$ except upper SEC $(P=0.124)$.

With respect to SEC, the heterogeneity of seroprevalence in upper and upper middle classes in different centers were $18 \%, 32 \%, 28 \%, 18 \%$, and $54 \%$ for EEDF, ICH, $\mathrm{KEM}, \mathrm{KKCTH}$, and SCC centers, respectively, reflecting endemicity differences in various regions of India. The pooled seropositivity across SECs was $26 \%$. The overall association of SEC with seroprevalence achieved statistical significance $(P=0.000)$, with the highest impact in Kolkata (upper and upper middle SEC 90/29; other SEC 210/116; $P=0.000)$.

The role of other variables, such as educational status of the parents, source of drinking water, and sanitary conditions, with HAV seropositivity (Figure 2) was also analyzed. The difference in seroprevalence of HAV in subjects from an educated background (35.7\%) and subjects from an illiterate background $(52.3 \%)$ was statistically significant across all the centers $(P=0.000)$. The seroprevalence of HAV was higher in subjects using a hand pump as the source of drinking water $(50 \%)$ than in those using other sources of drinking water (well water $22.2 \%$; river water $22.7 \%$; tap water $37 \%$ ). However; the source of drinking water for most subjects was tap water $(86.8 \%)$ and was not significantly associated with a higher HAV seroprevalence $(P=0.45)$ (Figure 2). 


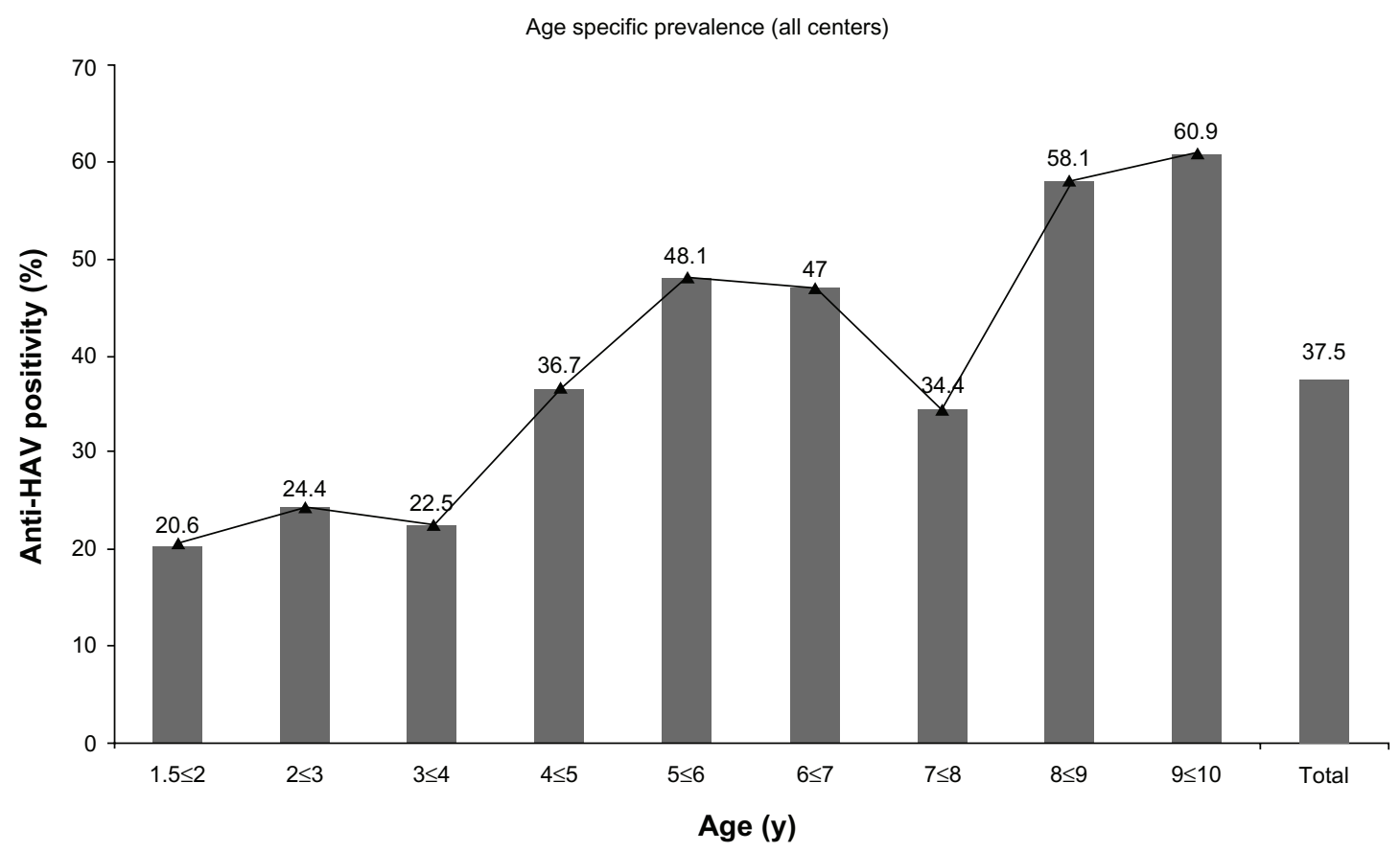

Figure I Age-specific prevalence (all centers).

Abbreviation: HAV, hepatitis $A$ virus.

Fewer subjects from a household with a private toilet within the house (33.1\%) were seropositive compared with those using an open field for defecation (75\%). The association of HAV seroprevalence was statistically significant $(P=0.001)$ with excreta disposal (Figure 2).

HAV seropositivity was not related to the sex of the subjects, either combined in all centers or when considered for each study center separately. The area of residence did not show a significant and clear association with HAV seroprevalence in most of the study centers. Only one of the study centers (KEM, Pune) showed a statistically significant ( $P=0.001$ ) association between area of residence and HAV seroprevalence. The binary logistic regression analysis revealed that SEC, age, source of drinking water, and education had a positive impact $(68.9 \%)$ on the seroprevalence of HAV (Table 2).

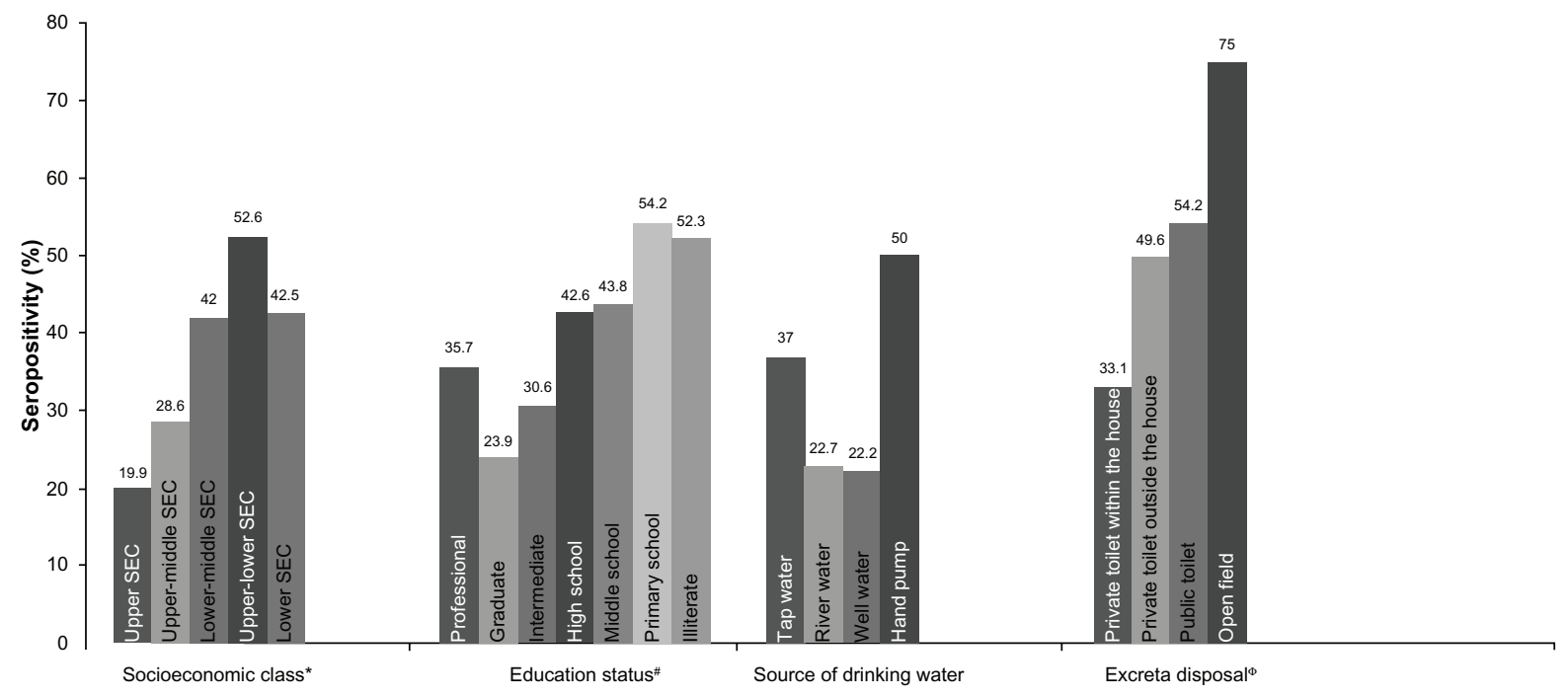

Figure 2 Overall impact of all factors on HAV seroprevalence.

Notes: *Overall association of SEC with seroprevalence was statistically significant $(P=0.000)$; ${ }^{*}$ difference in HAV seroprevalence among subjects from educated background and from illiterate background was statistically significant $(P=0.000)$; ${ }^{\Phi}$ association of HAV seroprevalence with excreta disposal was statistically significant $(P=0.00 \mathrm{I})$. Abbreviations: HAV, hepatitis A virus; SEC, socioeconomic class. 
Table 2 Association between seroprevalence and the determining factors for each center and combining all the centers (level of significance)

\begin{tabular}{llll}
\hline Factors & Coefficient & Significance & $\operatorname{Exp}(B)$ \\
\hline Socioeconomic class & -0.639 & $0.003^{* *}$ & 0.528 \\
Age & 0.842 & $0.000^{*}$ & 2.322 \\
Sex & 0.255 & 0.094 & 1.290 \\
Source of drinking water & 0.905 & $0.030^{*}$ & 2.471 \\
Toilet facility & -0.315 & 0.236 & 0.730 \\
Place of residence & -0.083 & 0.615 & 0.920 \\
Education & -0.296 & $0.040^{*}$ & 0.744 \\
Constant & -0.974 & 0.088 & 0.378 \\
Model summary & $\mathrm{I}, 087.864^{\mathrm{a}}$ & $0.127^{\mathrm{b}}$ & $0.173^{\mathrm{c}}$ \\
\hline
\end{tabular}

Notes: ${ }^{2} 2$ Log likelihood; ${ }^{\circ} \mathrm{Cox}$ and Snell R Square; $\mathrm{C}$ Nagelkerke R Square; $* P<0.05$; $* * p<0.01$.

Abbreviation: $\operatorname{Exp}(B)$, exponentiation of the $B$ coefficient.

\section{Discussion}

This study has demonstrated the current pattern of HAV seroprevalence in Indian children aged below 10 years, taking various SECs into consideration. A higher seroprevalence of HAV was observed among the older children than among the younger children $(1.5-2$ years $20.6 \%$; $9-10$ years $60.9 \%$; $P=0.000$ ), demonstrating a shift in HAV epidemiology as observed in previous studies. ${ }^{12,14,20,21}$

The results of a previous surveillance study demonstrated 98\% seropositive cases in the group aged 6-10 years in 1992 as compared with $50.4 \%$ in the present study. ${ }^{12}$ When compared with the seroprevalence in different cities among different age stratifications over a period of 10-15 years, a significant decline amongst all age groups of approximately $30 \%$ was noted. This difference in the number of HAVseropositive cases over age clearly demonstrates a shift in epidemiology. This may be due to an increase in non-immune subjects over the years, resulting in changing epidemiology that might lead to a profound impact on the magnitude and severity of the disease.

Studies worldwide have shown an association between higher SEC and decreased HAV seroprevalence. ${ }^{22}$ In India, various surveillance studies over the years in different cities documented a decline in anti-HAV prevalence, mostly because of the transition in demography. Improved hygiene through better education and sanitary conditions has led to an overall improvement in SEC. Dhawan et a ${ }^{14}$ demonstrated a significant effect of SEC on HAV seroprevalence; approximately $64.5 \%$ in the upper SEC and $85.3 \%$ in the lower SEC in the year 1998. The present study demonstrated seroprevalence of $25.7 \%$ in the upper SEC and $46.4 \%$ in the lower SEC. Although the association between seroprevalence and SEC remains the same as in the previous study, there has been significant decline of seropositivity in both SECs, confirming a decrease in hepatitis A transmission over the years.

Seroprevalence of HAV varied amongst different cities and within different communities of the same city. Heterogeneous pockets of susceptible individuals co-existed in different areas of Kolkata. This difference in anti-HAV prevalence was related to educational status and toilet facility. This indicated that awareness and education has an impact on the water hygiene and sanitary habits of the population, irrespective of SEC. Economic conditions and drinking water source did not show a significant effect on seroprevalence. In all centers, tap water was the primary source of drinking water, hence an association between source of drinking water and seroprevalence could not be established. However, that most subjects enrolled in the present study had access to tap water as a source of drinking water confirms improved facilities, leading to decreased transmission.

Although several studies have evaluated the seroprevalence of HAV, the effect of educational background has not been considered by most studies conducted in India. A study conducted in Turkey showed a statistically significant $(P=0.000)$ association between HAV seroprevalence and educational status of the mother (university graduate $23.1 \%$; illiterate $92.1 \%$ ) and father (university graduate $31.8 \%$; illiterate $92.3 \%$ ). ${ }^{23}$ In the present study, the lowest HAV seroprevalence was observed in EEDF, Kolkata, where the educational background of most parents was higher than in other centers (above secondary/total number of subjects, 61/72).

Hepatitis A remains asymptomatic among children below the age of 5 years; however, the severity of this infection increases with age and the disease assumes epidemic proportions. India has experienced HAV outbreaks in children, ${ }^{24}$ children and young adults, ${ }^{25}$ and adults. ${ }^{26}$ The World Health Organization (WHO) recommends large-scale hepatitis A vaccination in countries with improving SEC that have moved from high to intermediate hepatitis A endemicity. ${ }^{1}$ Documentation of large proportions of children still susceptible to HAV up to the age of 10 years, and evidence of outbreaks of HAV in the recent past, indicates the need for routine hepatitis A vaccination. Further, international data show that hepatitis A mass vaccination has significantly decreased the incidence of hepatitis A. Vaccination programs have decreased the incidence of HAV infection to a large extent in countries such as the USA (rate of HAV infection per 1,000,000 population reduced from 12 in 1995 to 1.5 in 2005), Israel (resulted in seroprotective antibody concentrations among $100 \%$ of children), and Argentina 
(average reduction rate between 1998 and 2002 of $88 \%$; $P<0.001){ }^{27-29}$

\section{Conclusion}

The present study demonstrates heterogeneity in the endemicity of HAV across different pockets of geographical distribution, various centers, and even within centers based on age, educational status, drinking water, and overall SEC status. The rate of seroprevalence has declined across all age group segments. Although the trend is higher in the age group 6-10 years, it has also shown a decrease of 30\% within the last decade. This transition in the rate of endemicity has been reported to increase the disease morbidity and mortality, which is otherwise in high endemic zones that are relatively asymptomatic. $^{30}$

The diverse variation in the rates of seropositivity across various cities in different locations of India in the urban settings confirms the need for routine vaccination. Considering the diversity of endemicity, there is scope for a single-dose vaccine schedule for both inactivated and live attenuated hepatitis A vaccine, as highlighted by the WHO for developing countries. ${ }^{1}$

\section{Acknowledgments}

This epidemiological research study was sponsored by Wockhardt Limited. All authors participated in the analysis and interpretation of data and critical revision of the manuscript. The authors extend acknowledgement to Professors Monoranjan Pal and Premananda Bharti from the Indian Statistical Institute for statistical analysis. The manuscript was read, revised, and approved by all authors. The authors acknowledge Knowledge Isotopes Pvt, Ltd (http://www. knowledgeisotopes.com) for the writing support.

\section{Disclosure}

$\mathrm{SB}, \mathrm{AG}, \mathrm{SB}, \mathrm{AC}$, and $\mathrm{JC}$ have received a research grant for conducting the research study. SC and MM are employees of Medclin Research Pvt, Ltd, a Clinical Research Organization. $\mathrm{MM}$ is the corresponding author and has received payment from Wockhardt Limited for project management services provided by Medclin Research Pvt, Ltd. GK, AM, and SR are employees of Wockhardt Limited. VA has received a research grant for conducting the laboratory investigation.

\section{References}

1. No authors listed. WHO position paper on hepatitis A vaccines Jun 2012. Wkly Epidemiol Rec. 2012;87:261-276.

2. Jacobsen KH, Wiersma ST. Hepatitis A virus seroprevalence by age and world region, 1990 and 2005. Vaccine. 2010;28:6653-6657.
3. Jacobsen K. The Global Prevalence of Hepatitis a Virus Infection and Susceptibility: A Systematic Review. Immunization, Vaccines and Biologicals. Geneva: World Health Organization; 2009. Available from: http://whqlibdoc.who.int/hq/2010/WHO_IVB_10.01_eng.pdf. Accessed December 26, 2012.

4. Kar P. Is there a change in seroepidemiology of hepatitis A infection in India? Indian J Med Res. 2006;123:727-729.

5. Mathur P, Arora NK. Epidemiological transition of hepatitis A in India: issues for vaccination in developing countries. Indian $\mathrm{J} \mathrm{Med}$ Res. 2008;128:699-704.

6. Chitambar SD, Chadha MS, Joshi MS, Arankalle VA. Prevalence of hepatitis A antibodies in western Indian population: changing pattern. Southeast Asian J Trop Med Public Health. 1999;30:273-276.

7. Murhekar MV, Sehgal SC, Murhekar KM, Padbhidri SP, Chitambar SD, Arankalle VA. Changing scenario of hepatitis A virus and hepatitis E virus exposure among the primitive tribes of Andaman and Nicobar Islands, India over the 10-year period 1989-1999. JViral Hepat. 2009;9: 315-321.

8. Franco E, Meleleo C, Serino L, Sorbara D, Zaratti L. Hepatitis A: epidemiology and prevention in developing countries. World J Hepatol. 2012;4:68-73.

9. Acharya SK, Madan K, Dattagupta S, Panda SK. Viral hepatitis in India. Natl Med J India. 2006;19:203-217.

10. World Health Organization. Evidence Based Recommendation for Use of Hepatitis A Vaccines in Immunization Services: Background Paper for SAGE Discussions. Geneva: World Health Organization; 2011. Available from: http://www.who.int/immunization/sage/1_ HepABackground_17Oct_final2_nov11.pdf. Accessed December 26, 2012.

11. Syed R, Mohammed A, Sindiri P, et al. Seroepidemiology of hepatitis A virus in Hyderabad, South India. J Med Allied Sci. 2012;2:58-61.

12. Arankalle VA, Tsarev SA, Chadha MS, et al. Age-specific prevalence of antibodies to hepatitis A and E viruses in Pune, India, 1982 and 1992. J Infect Dis. 1995;171:447-450.

13. Arankalle VA, Chadha MS, Chitambar SD, Walimbe AM, Chobe LP, Gandhe SS. Changing epidemiology of hepatitis A and hepatitis E in urban and rural India (1982-1998). J Viral Hepat. 2001;8:293-303.

14. Dhawan PS, Shah SS, Alvares JF, et al. Seroprevalence of hepatitis A virus in Mumbai, and immunogenicity and safety of hepatitis A vaccine. Indian J Gastroenterol. 1998;17:16-18.

15. Acharya SK, Batra Y, Bhatkal B, et al. Seroepidemiology of hepatitis A virus infection among school children in Delhi and north Indian patients with chronic liver disease: implications for HAV vaccination. J Gastroenterol Hepatol. 2003;18:822-827.

16. Dutta AK, Aggarwal A, Kapoor AK, Ray GN, Batra S. Seroepidemiology of hepatitis A in Delhi. Indian J Pediatr. 2000;67:77-79.

17. Gupta A, Chawla Y. Changing epidemiology of hepatitis A infection. Indian J Med Res. 2008;128:7-9.

18. Krleza-Jerić K, Lemmens T. 7th revision of the Declaration of Helsinki: good news for the transparency of clinical trials. Croat Med J. 2009;50:105-110.

19. Kumar N, Gupta N, Kishore J. Kuppuswamy's socioeconomic scale: updating income ranges for the year 2012. Indian J Public Health. 2012;56:103-104.

20. Aggarwal R, Naik S, Yachha SK, Naik SR. Seroprevalence of antibodies to hepatitis A virus among children in Northern India. Indian Pediatr. 1999;36:1248-1250.

21. Mall ML, Rai RR, Philip M, et al. Seroepidemiology of hepatitis A infection in India: changing pattern. Indian J Gastroenterol. 2001;20: 132-135.

22. Jacobsen KH, Koopman JS. Declining hepatitis A seroprevalence: a global review and analysis. Epidemiol Infect. 2004;132: $1005-1022$.

23. Altinkaynak S, Selimoğlu MA, Ertekin V, Kiliçaslan B. Epidemiological factors affecting hepatitis A seroprevalence in childhood in a developing Country. Eurasian J Med. 2008;40:25-28. 
24. Chadha MS, Arankalle VA, Jadi RS, Joshi MV, Thakare JP, et al. An outbreak of Chandipura virus encephalitis in the eastern districts of Gujarat state, India. Am J Trop Med Hyg. 2005;73:566-570.

25. Chobe LP, Arankalle VA. Investigation of a hepatitis A outbreak from Shimla Himachal Pradesh. Indian J Med Res. 2009;130: 179-184.

26. Arankalle VA, Sarada Devi KL, Lole KS, Shenoy KT, Verma V, Haneephabi M. Molecular characterization of hepatitis A virus from a large outbreak from Kerala, India. Indian J Med Res. 2006;123:760-769.

27. Wasley A, Miller JT, Finelli L; Centers for Disease Control and Prevention (CDC). Surveillance for acute viral hepatitis: United States, 2005. MMWR Surveill Summ. 2007;56:1-24.
28. Dagan R, Greenberg D, Weber F. Immunogenicity of an inactivated hepatitis A pediatric vaccine: three-year post-booster follow-up. Vaccine. 2005;23:5144-5148.

29. Vacchino MN. Incidence of hepatitis A in Argentina after vaccination. J Viral Hepat. 2008;15 Suppl 2:47-50.

30. Verma R, Khanna P. Hepatitis A vaccine should receive priority in National Immunization Schedule in India. Hum Vaccin Immunother. 2012;8:1132-1134.

\section{Publish your work in this journal}

Vaccine: Development and Therapy is an international, peer-reviewed, open access journal that spans the spectrum of vaccine design and development through to clinical applications. The journal is characterized by the rapid reporting of application notes, reviews, original research and clinical studies in all therapeutic areas. Clinical outcomes, patient safety,
Dovepress

and programs for the development and effective, safe, and sustained use of vaccines will be a feature of the journal. The manuscript management system is completely online and includes a very quick and fair peer-review system. Visit http://www.dovepress.com/testimonials.php to read real quotes from published authors.

Submit your manuscript here: http://www.dovepress.com/vaccine-development-and-therapy-journal 